\title{
Silicon Nanofluidic Membrane for Electrostatic Control of Drugs and Analytes Elution
}

\author{
Nicola Di Trani ${ }^{1,2}{ }^{\oplus}$, Antonia Silvestri ${ }^{1,3}{ }^{-}$, Yu Wang ${ }^{1}{ }^{(}$, , Danilo Demarchi $^{3}$, Xuewu Liu ${ }^{1}$ and \\ Alessandro Grattoni $1,4,5, *$ (D) \\ 1 Department of Nanomedicine, Houston Methodist Research Institute, Houston, TX 77030, USA; \\ nditrani@houstonmethodist.org (N.D.T.); antonia.silvestri@polito.it (A.S.); \\ ywang2@houstonmethodist.org (Y.W.); xliu@houstonmethodist.org (X.L.) \\ 2 University of Chinese Academy of Science (UCAS), Shijingshan, 19 Yuquan Road, Beijing 100049, China \\ 3 Department of Electronics and Telecommunications, Polytechnic of Turin, 10129 Turin, Italy; \\ danilo.demarchi@polito.it \\ 4 Department of Surgery, Houston Methodist Hospital, Houston, TX 77030, USA \\ 5 Department of Radiation Oncology, Houston Methodist Hospital, Houston, TX 77030, USA \\ * Correspondence: agrattoni@houstonmethodist.org; Tel.: +1-(713)-441-7324
}

Received: 8 June 2020; Accepted: 15 July 2020; Published: 19 July 2020

\begin{abstract}
Individualized long-term management of chronic pathologies remains an elusive goal despite recent progress in drug formulation and implantable devices. The lack of advanced systems for therapeutic administration that can be controlled and tailored based on patient needs precludes optimal management of pathologies, such as diabetes, hypertension, rheumatoid arthritis. Several triggered systems for drug delivery have been demonstrated. However, they mostly rely on continuous external stimuli, which hinder their application for long-term treatments. In this work, we investigated a silicon nanofluidic technology that incorporates a gate electrode and examined its ability to achieve reproducible control of drug release. Silicon carbide ( $\mathrm{SiC}$ ) was used to coat the membrane surface, including nanochannels, ensuring biocompatibility and chemical inertness for long-term stability for in vivo deployment. With the application of a small voltage $(\leq 3 \mathrm{~V} \mathrm{DC})$ to the buried polysilicon electrode, we showed in vitro repeatable modulation of membrane permeability of two model analytes-methotrexate and quantum dots. Methotrexate is a first-line therapeutic approach for rheumatoid arthritis; quantum dots represent multi-functional nanoparticles with broad applicability from bio-labeling to targeted drug delivery. Importantly, $\mathrm{SiC}$ coating demonstrated optimal properties as a gate dielectric, which rendered our membrane relevant for multiple applications beyond drug delivery, such as lab on a chip and micro total analysis systems ( $\mu \mathrm{TAS})$.
\end{abstract}

Keywords: electrostatic gating; nanofluidic diffusion; controlled drug release; silicon membrane; smart drug delivery

\section{Introduction}

Chronic pathologies affect nearly half of the population worldwide [1,2] and represent one of the leading causes of death and disability [3]. Management of chronic conditions is challenged by co-morbidities [4], poor adherence to treatment [5], and a lack of therapeutic technologies suitable to address the complexity of the disease [6]. Long-acting controlled therapeutic administration represents a promising strategy for medical conditions requiring repeated daily dosing $[7,8]$. In view of this, long-acting platforms for sustained drug release have been developed, leading to significant improvements in the management of conditions, such as hormone deficiency and infectious diseases [9-11]. However, the pathophysiology of most chronic diseases is determined by circadian 
biological cycles [12], which have a significant impact on the efficacy of treatment and associated adverse effects [13]. This is the case for pathologies, such as diabetes and metabolic disorders [14], hypertension, psychiatric and neurodegenerative conditions [15], rheumatoid arthritis [16], and chronic pain [17], to name a few, where the timing of drug administration is key to elicit the intended therapeutic effect.

Advanced technologies enabling personalized adjustments of therapeutic administration, both in time and dose, represent a desirable but unmet clinical need [18,19]. Ideally, these technologies should incorporate a drug delivery mechanism that can be rapidly and easily tuned to release the required dosage, at the right time, without requiring continuous external stimuli. Further, they should allow for pre-programmed dosing schedules as well as remote control capabilities, to enable healthcare providers to adjust medication through telemedicine approaches [20]. Devices with such capabilities could eradicate treatment compliance issues and dramatically improve the therapeutic index and the quality of life of patients, while substantially reducing healthcare expenditure.

Current approaches developed for controlled drug administration are based on modulation of permeability of membranes via sustained external stimuli. These systems mostly rely on polymeric membrane architectures and achieve changes in pore size and conformation via temperature variation triggered by a magnetic field [21], near-infrared irradiation [22-24], or ultrasound [25]. Other devices use a magnetic field to reversibly or irreversibly obstruct the pores of a membrane using microparticles [26] or low melting temperature polymers [27]. Albeit promising, these strategies are limited by the need for continuous external activation and associated cumbersome external equipment. Electrical actuation offers a solution to these limitations, enabling control via miniaturized circuitry and low energy radio-frequency (RF) communications. In this context, various technologies have been created, either integrating gate electrodes [28] or polypyrrole (PPy) [29,30] on anodic aluminum oxide (AAO) membranes. However, polydispersity in pore size common to AAO membranes represents a limitation to achieve fine control of drug release [28,31].

In this study, we investigated the performance of a silicon nanofluidic membrane that uses electrostatic gating [32] to modulate the transport of charged molecules by modifying nanochannel permeability. Microfabricated using standard semiconductor manufacturing techniques, this membrane features hundreds of thousands of identical slit-nanochannels geometrically distributed across the membrane surface to maximize porosity while maintaining mechanical integrity. A buried polysilicon layer extends over the entire nanochannel surface and acts as a single distributed gate electrode. An outermost layer of biocompatible silicon carbide ( $\mathrm{SiC}$ ) is adopted to bury and insulate the gate electrode and minimize leakage while providing chemical inertness for applications in vivo or in contact with biological fluids. SiC insulation properties were studied in comparison with silicon dioxide $\left(\mathrm{SiO}_{2}\right)$, the most common gate dielectric material in metal-oxide-semiconductor field-effect transistor (MOSFET). Further, energy consumption leakage current and gating performance were assessed at different gate potentials. Finally, we adopted two relevant model analytes-methotrexate and quantum dots-to assess the in vitro transport modulation performances. Methotrexate represents an important therapeutic agent commonly used for rheumatoid arthritis [33], whereas quantum dots are adopted for a variety of biomedical imaging applications as well as drug delivery and theranostics [34,35]. In light of the promising results and the ease of integration within implantable devices, our gated membrane might constitute a promising step forward in the development of flexible technologies for the treatment of chronic diseases. Further, our nanofluidic technology could be adopted in other applications for lab on a chip [36] and micro total analysis systems ( $\mu$ TAS) devices for electrokinetic separation processes [37], bio-sample sorting and analysis [38], among others.

\section{Materials and Methods}

\subsection{Nanofluidic Membrane Fabrication}

Silicon membranes fabrication was performed using standard semiconductor techniques. The fabrication process is described step-by-step elsewhere [39]. Briefly, a dense array of nanochannels 
(500 $\mathrm{nm}$ width, $6 \mu \mathrm{m}$ length) was obtained by vertically etching via deep reactive ion etching (DRIE) the device layer $(10 \mu \mathrm{m})$ of a silicon on insulator (SOI) wafer (total thickness $411 \mu \mathrm{m}$ ). The etching was stopped at the middle oxide layer $(1 \mu \mathrm{m})$. The handle wafer $(400 \mu \mathrm{m})$ on the opposite side of the SOI was etched using DRIE up to the oxide layer to create a hexagonal pattern of densely packed circular microchannels. To connect the nanochannels to the microchannels, the buried oxide layer was etched by a buffered oxide etchant solution (BOE). The resulting nanochannels size $(770 \mathrm{~nm})$ was reduced by three subsequent processes. First, wet thermal oxidation generated a $175 \mathrm{~nm}$ layer of $\mathrm{SiO}_{2}$, and then a $121 \mathrm{~nm}$ layer of polycrystalline silicon (poly-Si) was obtained via low-pressure chemical vapor deposition (LPCVD). Plasma-enhanced chemical vapor deposition (PECVD) was then used for the silicon carbide coating $(\mathrm{SiC}, 64 \mathrm{~nm})$. Electrode pads were exposed via selective etching of $\mathrm{SiC}$ via fluorine-based RIE. Wafers were then diced into individual membranes (ADT 7100 Dicing Saw, Advanced Dicing Technologies, Zhengzhou, China), obtaining individual silicon membranes of $6 \mathrm{~mm}$ $\times 6 \mathrm{~mm} \times 411 \mu \mathrm{m}$. Each membrane featured a total of 278,600 identical slit nanochannels $10 \mu \mathrm{m}$ long and $6 \mu \mathrm{m}$ wide. Nanochannels were arranged in groups of 1400, where each group led to one circular microchannel on the opposite side of the chip. Finally, microchannels were geometrically organized in a hexagonal pattern to maximize porosity and structural integrity. In this study, membranes with a final layer of $\mathrm{SiO}_{2}$ were also used and obtained by wet thermal oxidation of poly-Si.

\subsection{Assessment of Membrane Structure}

Morphological assessment and characterization of the nanochannel multi-layer structure were performed via scanning electron microscopy (SEM). A focused ion beam (FIB) system FEI 235 (Nanofabrication facility of the University of Houston, Houston, TX, USA) was used to simultaneously create nanochannels' cross-sections and acquire images. Gallium ion milling was performed on the micromachine parts of the membrane and to expose the nanochannel cross-section. Imaging was then performed at a $52^{\circ}$ angle.

\subsection{Electrode Connection}

Electrical wires (36 AWG, McMaster Carr, Elmhurst, IL, USA) were epoxied to the membrane pads using a silver-based conductive adhesive (H20E, Epoxy Technology, Inc., Billerica, MA, USA) and cured at $150^{\circ} \mathrm{C}$ for $1 \mathrm{~h}$. Electrode insulation was achieved by applying a thin layer of UV epoxy (OG116, Epoxy Technologies, Inc. Billerica, MA, USA) over the conductive pad and UV-curing (UVP UVL-18 EL Series, Analytik Jena US LLC, Upland, CA, USA) for $120 \mathrm{~min}$. The correct electrode connection was tested by measuring the resistance between the two connection pads with a Fluke 177 True RMS Multimeter (Fluke Corporation, Everett, WA, USA).

\subsection{Electrochemical Characterization}

A custom dual-reservoir polymethyl methacrylate (PMMA) apparatus [39] was employed to perform electrochemical measurements. Membranes were clamped between the two $2 \mathrm{~mL}$ reservoirs of the testing apparatus, each containing two $\mathrm{Ag} / \mathrm{AgCl}$ electrodes (64-1313, Harvard Apparatus, Holliston, MA, USA). All measurements were performed in PBS, except for conductance studies, where $\mathrm{KCl}$ solutions at different concentrations (from $10^{-6}$ to $10^{-1} \mathrm{M}$ ) were used. A benchtop electrochemical tester (CH Instruments, Inc. 660E, Austin, TX, USA) was used in either 3 or 4 electrode configurations.

Impedance was measured with a 4-electrodes configuration. A $50 \mathrm{mV}$ perturbation signal was applied through the electrochemical analyzer within a frequency window from $10 \mathrm{mH}$ to $10 \mathrm{kH}$. The measurements were performed with a superimposed DC voltage in the range $-3 \mathrm{~V}$ to $3 \mathrm{~V}$ in steps of 1 V. Fittings to a Randles cell model were performed with the CHI 660E software (CH Instruments, Inc. 660E, Austin, TX, USA).

Leakage current was measured with a 3-electrodes configuration. Voltages were applied using the $\mathrm{CHI} 660 \mathrm{E}$ between the electrode pad and $\mathrm{Ag} / \mathrm{AgCl}$ electrodes in solution at a distance of $\sim 1 \mathrm{~cm}$ 
from the membrane. Measurements were performed in the $-3 \mathrm{~V}$ to $+3 \mathrm{~V}$ range in $1 \mathrm{~V}$ steps, and each step lasted for $120 \mathrm{~s}$, allowing for transient phenomena to resolve and obtain a stable measurement.

For conductance experiments, we employed a 4-electrodes configuration. Measurements were performed for $\mathrm{KCl}$ concentrations from $1 \mu \mathrm{M}$ to $100 \mathrm{mM}$ from the lower to the highest ionic strength. Reservoirs were rinsed with deionized water for $1 \mathrm{~min}$, and the solution was replaced after each measurement. Steps of $400 \mathrm{mV}$ were applied using the $\mathrm{CHI} 660 \mathrm{E}$ from $-2 \mathrm{~V}$ to $2 \mathrm{~V}$, with 30 s pauses to exhaust possible transient effects. Conductance measurements were performed with a floating gate, and the values calculated for each step and averaged.

Cyclic voltammetry measurements were conducted with a 3-electrodes configuration and a scanning rate of $50 \mathrm{mV} / \mathrm{s}$ within the interval $-2 \mathrm{~V}$ to $2 \mathrm{~V}$. Electrochemical measurements were carried out on membranes with a final dielectric layer of both $\mathrm{SiC}$ and $\mathrm{SiO}_{2}$.

\subsection{In Vitro Release Modulation}

In vitro release modulation experiments were performed employing a custom dual-reservoir device described in detail elsewhere [40]. Nanochannel membranes were individually clamped between a $250 \mu \mathrm{L}$ drug reservoir and a UV-Vis transparent macro-cuvette serving as the sink reservoir. Two O-rings were used to prevent fluid leakage between membranes and the reservoir. Fluid evaporation was prevented by sealing a drug reservoir with biocompatible silicone plugs (McMaster Carr, Elmhurst, IL, USA).

Experiments were performed using SiC-coated membranes with $\sim 300 \mathrm{~nm}$ nanochannels. To ensure proper channel wetting, membranes were immersed in isopropyl alcohol for $1 \mathrm{~h}$ and then rinsed three times in deionized $\mathrm{H}_{2} \mathrm{O}$. Membranes were then placed overnight in $0.01 \times$ PBS or $1 \times$ PBS in preparation for quantum dots and methotrexate release, respectively. Sink reservoirs $(4.45 \mathrm{~mL})$ were filled with matching PBS solutions. After fixture assembly, the source reservoir was loaded with either $1 \mathrm{mg} / \mathrm{mL} 0.01 \times$ PBS solution of quantum dots (CdTe core-type, COOH functionalized, 777978-10MG, Sigma Aldrich, St. Louis, MO, USA) or $2.5 \mathrm{mg} / \mathrm{mL}$ PBS solution of methotrexate (13960, Cayman Chemical, Ann Arbor, MI, USA). Both molecules possess a negative charge at $\mathrm{pH} 7.4$, with methotrexate presenting a stable $-2 q$ charge $\left(-3.2 \times 10^{-19} \mathrm{C}\right)$ and quantum dots having a charge that ranges from $-5 q$ to $-15 q$ depending on $\mathrm{pH}$ and ionic strength [41]. Methotrexate has a molar mass of $454 \mathrm{Da}$ and an estimated diameter of $1.6 \mathrm{~nm}$ [42], while quantum dots have an estimated molar mass of $200 \mathrm{kDa}$ and an estimated diameter of $4.7 \mathrm{~nm}$ [43]. An Ag/AgCl reference electrode (Harvard Apparatus, Holliston, MA, USA) was used and placed in the source drug reservoir.

Absorbance measurements of every sample were performed at 5 min intervals using a custom UV-vis spectrophotometer apparatus consisting of a robotic carousel [44] connected to an Agilent Cary 50 spectrophotometer (Agilent, Technologies, Santa Clara, CA, USA). Sink solution homogeneity was maintained by constant magnetic stirring (600 rpm). Methotrexate absorbance was measured at $373 \mathrm{~nm}$, while quantum dots at $240 \mathrm{~nm}$. An electrical potential (0,-1.5, or $-3 \mathrm{~V} \mathrm{DC})$ was applied between the $\mathrm{Ag} / \mathrm{AgCl}$ and the membrane electrodes through a waveform generator (33522A, Keysight Technologies, Santa Clara, CA, USA). Passive (0 V) and active ( -1.5 or $-3 \mathrm{~V})$ phases were alternated at regular intervals. For methotrexate, phases were alternated every $6 \mathrm{~h}$ between passive and active $(0$ and $-3 \mathrm{~V} \mathrm{DC}$, respectively). For quantum dots, $12 \mathrm{~h}$ passive phases were alternated with $8 \mathrm{~h}$ of active applied potential $(-1.5 \mathrm{~V})$.

\subsection{Statistical Analysis}

Statistical analysis was performed using GraphPad Prism 8 (version 8.1.1; GraphPad Software, Inc., San Diego, CA, USA). Mean \pm SD values were calculated for all results. Further statistical significance was assessed, adopting the two-tailed paired t-tests $\left({ }^{* *} p \leq 0.01 ;{ }^{* * *} p \leq 0.0001\right)$. Cumulative releases were split into phases, and each fitted by a first-order polynomial (MATLAB ${ }^{\circledR}$ polyfit, MathWorks, Natick, MA, USA). Slopes of cumulative release curves were normalized and displayed as a percentage of the passive release profiles. 


\section{Results and Discussion}

\subsection{Nanofluidic Membrane}

Prior to investigating the electrical performance of the membranes, we sought to analyze the quality of the membrane fabrication process (Figure 1). Individual silicon membranes were first visually inspected to assess integrity. Figure $1 \mathrm{~A}$ shows a stereomicroscope picture of a single membrane, highlighting the conductive electrode pads at the top right and bottom left edges. The hexagonal arrangement of microchannels allowed us to maximize packing density without compromising mechanical robustness. By measuring transmembrane nitrogen gas flow and adopting our predictive model for nanofluidic gas transport [45], we obtained an indirect measurement for the size of nanochannels $(\sim 300 \mathrm{~nm})$. Sample membranes were further analyzed with SEM imaging. Figure 1B shows the tightly packed nanochannel arranged in arrays of 19 rows and 96 columns with a horizontal pitch of $2 \mu \mathrm{m}$ and a vertical pitch of $10 \mu \mathrm{m}$. No macroscopic defects or pinholes were observed across wafers, which indicated that the fabrication protocol was repeatable.

The analysis of the membrane cross-sections obtained via FIB milling was performed to evaluate the uniformity of layer deposition at different nanofabrication steps. $\mathrm{SiO}_{2}$ growth via thermal oxidation resulted in a highly uniform layer along the whole length of the vertical nanochannels (Figure 1C). Thermal oxidation is a slow process that enables precise control over layer thickness. Thus, it allowed us to accurately and homogeneously reduce the size of nanochannels. The subsequent deposition of poly-Si (Figure 1D) was used to create a gate electrode that coats the whole nanofluidic structure with the objective of maximizing the electrostatic gating performances. Uniform poly-Si deposition through the chemical vapor deposition-based (CVD) process in high-aspect-ratio hollow structures can be challenging. However, our imaging analysis showed that the deposited layer was uniform (Figure 1D), except for a slight increase in thickness at the nanochannel outlet (bottom right). Finally, a thin layer of $\mathrm{SiC}$ (Figure 1E) was used to coat the conductive poly-Si and act as an insulating and chemical inert layer. Despite the high-aspect-ratio of the slit nanochannels, the deposition of SiC was also achieved with good uniformity (Figure 1E). Slight material accumulations at the inlet and outlet of nanochannels were expected. While we did not generate these intentionally, we noted that a local restriction at the nanochannel extremities could improve gating performance.

All materials used for the fabrication of the nanofluidic membrane have previously been demonstrated to be biocompatible using ISO 10993 standards by Kotzar et al. [46]. A subset of these materials has also been investigated in vivo in rodents and has shown biocompatibility and low biofouling [47]. Moreover, in our fabrication protocol, silicon carbide completely encapsulates the membrane and, therefore, is the only material exposed to the environment. Silicon carbide was specifically chosen for this encapsulation purpose as it's considered a versatile material for biomedical applications where extended exposure to physiological fluids is needed [48,49]. Additionally, in vivo biocompatibility of $\mathrm{SiC}$ was demonstrated by Cogan et al. [50], who subcutaneously implanted SiC discs in New Zealand White rabbit, the histological evaluation showed no chronic inflammatory response, and a capsule thickness comparable to controls was found.

Furthermore, silicon carbide has previously been shown to offer reduced biofouling when compared to other biocompatible materials, such as silicon or silicon dioxide [51]. Although complete protection against protein adsorption could not be achieved [52], we previously showed that biofouling did not negatively affect the function of our devices. Specifically, nanofluidic membranes, similar to the one presented in this study, have been used in-vivo in rats for up to 6 months [53] and in non-human primates for up to 4 months [54] with no alteration of drug release from biofouling or fibrotic tissue encapsulation.

When compared to membrane architectures previously developed in our lab [55-57], this membrane presented a less cumbersome fabrication process, thanks to the direct alignment of nanochannels and microchannels [58,59]. Further, a substantially higher nanochannels density $[55,60]$ was achieved. In contrast with other gated membrane based on porous alumina (AAO) [29], presenting 
an irregular pore size distribution [28], our structure achieved a monodispersed nanochannel size that could aid in better control of molecular transport. In its current configuration, featuring 278,600 nanochannels, our membrane configuration was designed to achieve high mass transport rates per unit surface area. This is typically preferable in the context of implantable drug delivery application, where miniaturization is a requirement [39]. However, in light of its modular structure, the same fabrication process could be employed to create alternative configurations with a different number of channels for adoption in electrokinetic-enabled molecular manipulation or sorting applications. For these purposes, the large gate electrode surface area might provide increased electrostatic control of fluid molecules as compared to common Polydimethylsiloxane-glass (PDMS-glass) systems [61,62] which feature localized gate electrodes.

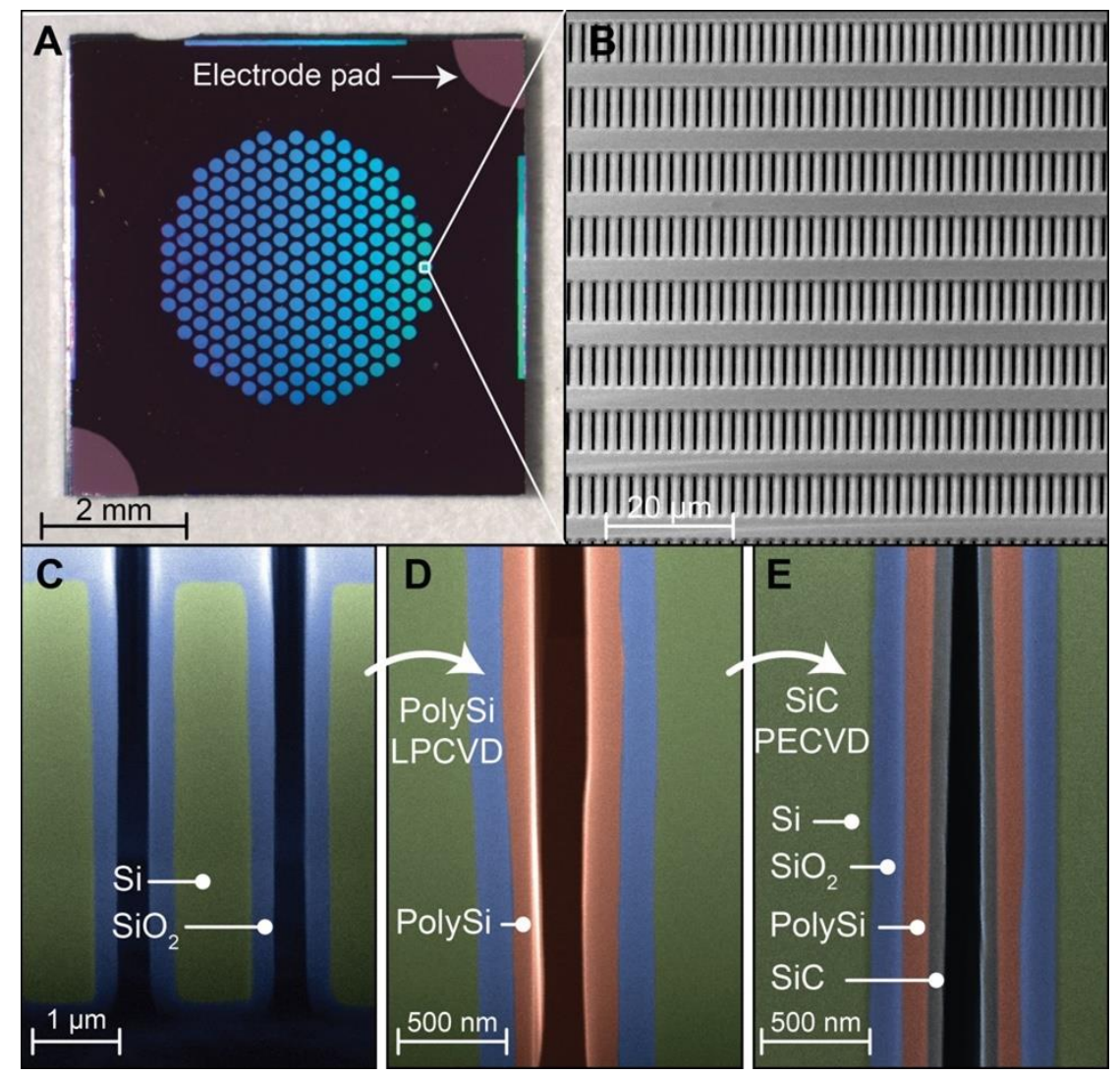

Figure 1. Nanochannel membrane structure. (A) Optical image of a silicon nanofluidic membrane, presenting electrode pads with exposed conductive polysilicon. (B) SEM micrograph, showing the array of nanochannel inlets. (C,D,E) Vertical cross-section image (SEM) obtained along the length of nanochannel, showing the membrane fabrication at different stages. Micrographs were color-enhanced for clarity of visualization. (C) Thermally grown $\mathrm{SiO}_{2}$ layer $(\sim 175 \mathrm{~nm}$, blue); (D) Low-pressure chemical vapor deposition (LPCVD)-deposited poly-Si layer ( 121 nm, red); (E) Plasma-enhanced-CVD deposited SiC coating ( $\sim 64 \mathrm{~nm}$, gray). Images C, D, and E do not picture the same membrane location.

\subsection{Solid-Liquid Interface, $\mathrm{SiO}_{2}$ vs $\mathrm{SiC}$}

To evaluate $\mathrm{SiC}$ properties as a gate dielectric in contact with ionic solutions, we compared its insulation performance to $\mathrm{SiO}_{2}$, which is a broadly used gate dielectric in solid electronics [63]. $\mathrm{SiO}_{2}$ and other metal oxides, such as alumina and hafnium dioxide, owe their success to their high dielectric constants that allow for low leakage currents. Even though these materials excel in solid electronic manufacturing, they either lack biocompatibility or chemical inertness and durability in aqueous environments [50]. 
Leakage current measurements (Figure 2A) performed with our membranes did not show substantial differences between $\mathrm{SiO}_{2}$ and $\mathrm{SiC}$, except for $3 \mathrm{~V}$. However, the steep increase in leakage observed for $\mathrm{SiC}$ between 2 and $3 \mathrm{~V}$, emphasized by the electrolytic solution environment, suggests that the molecular arrangement in the dielectric layer is not ideal [64]. The literature on gate dielectric leakage in ionic solutions is scarce, and the available models for a solid-state field-effect transistor (FET) are unable to account for the effect of the electrolyte solution environment. In aqueous solutions, currents in the order of $\mu \mathrm{A}$ were measured for electric fields as low as $0.5 \mathrm{MV} \mathrm{cm}^{-1}$ (Figure 2A). In contrast, for solid-state FET, currents in the order of magnitude of $\mu \mathrm{A}$ are only expected for electric fields greater than 15 and $2 \mathrm{MV} \mathrm{cm}^{-1}$ for $\mathrm{SiO}_{2}$ and $\mathrm{SiC}$, respectively. High leakage currents are usually attributed to the formation of conductive filaments within the oxide, whereby electrons are trapped and form clusters within defects in the material. When clusters are at tunneling distance, a conductive path can form, leading to high leakage currents $[65,66]$. The proportional increase in leakage currents at increasing ionic strength of the solution, previously reported by this group [39], provides further support for this phenomenon.
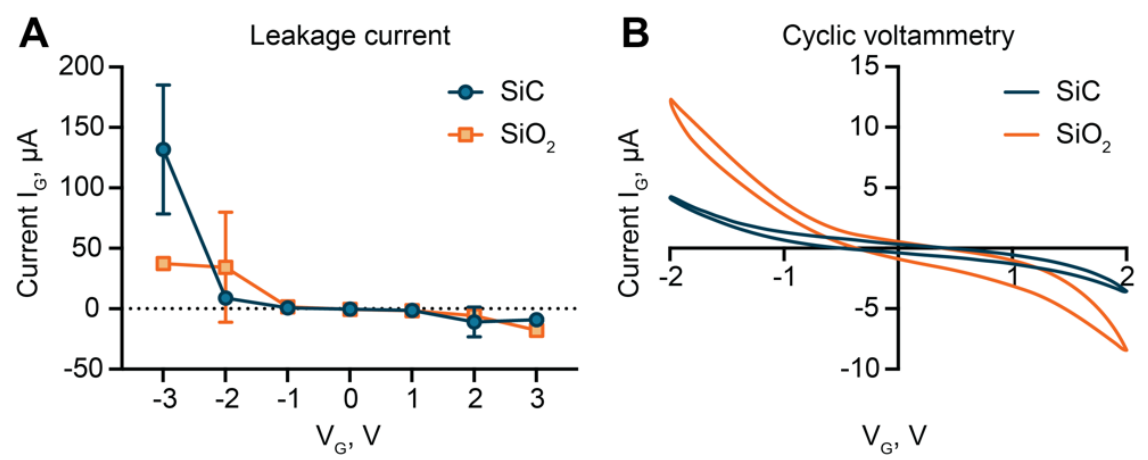

Figure 2. Leakage current and cyclic voltammetry. (A) Comparison of gate leakage current for $\mathrm{SiO}_{2}$ and silicon carbide ( $\mathrm{SiC}$ ) dielectric. (B) Cyclic voltammetry comparison between $\mathrm{SiO}_{2}$ and $\mathrm{SiC}$.

In the voltage range between -2 and $2 \mathrm{~V}, \mathrm{SiC}$ and $\mathrm{SiO}_{2}$ exhibited similar values of leakage currents. Thus, to closer investigate differences in performances, we used cyclic voltammetry (CV). As compared to $\mathrm{SiO}_{2}$-coated membranes, lower currents were measured for $\mathrm{SiC}$ at each applied voltage (Figure 2B). Interestingly, we observed a non-linear proportional relationship between voltage and current for both materials. $\mathrm{SiC}$ exhibited a steep increase in current for voltages higher than $1 \mathrm{~V}$ in absolute value. This suggested that for small applied voltages, no faradaic currents occurred, and the material behaved almost as an ideal capacitor. For voltages above $\pm 1 \mathrm{~V}$, electrochemical reactions between the surface groups $\left(\mathrm{C}, \mathrm{SiO}^{-}\right)$and reactive species in the electrolyte solution $\left(\mathrm{Cl}^{-}, \mathrm{HO}^{-}\right)$led to increased currents.

In contrast, the significant current increase observed for the leakage currents (Figure 2A) for voltages over $2 \mathrm{~V}$ was likely related to material deterioration and conductive filament formation. The asymmetry between results obtained with positive and negative voltages provided further support for this theory. Higher currents for negative applied voltages were observed in both measurements. For negative voltages, positive species were attracted to the surface. The percolation model suggests that in the presence of strong electrostatic attraction, protons can diffuse in the insulator, starting a percolating path that can lead to the formation of a conductive filament [65]. Instead, for positive potentials, proton repulsion may cause a reversible interruption of the conductive filament, effectively decreasing leakage [67]. Additionally, the difference in hysteresis between the two CV profiles (Figure 2B) was suggestive of differences in surface charge accumulation between the two materials. A thinner CV profile usually correlates with low charge accumulation. Collectively, the results showed that $\mathrm{SiC}$ suffered lower leakage currents in the $-2 \mathrm{~V}$ to $2 \mathrm{~V}$ range, exhibiting better insulation performance than $\mathrm{SiO}_{2}$. 


\subsection{Electrochemical Characterization: Conductance}

To further investigate the surface properties of $\mathrm{SiC}$, we performed conductance measurements of $\mathrm{SiC}$-coated membranes in the ionic concentration range between $1 \mu \mathrm{M}$ and $100 \mathrm{mM}$. We employed a custom fixture [39] that allowed us to limit wetting to the nanochannel part of the membrane. The results are shown in Figure 3A. At high ionic strengths $\left(>10^{-4} \mathrm{M}\right)$, conductance measurements displayed a linear dependence on the ionic strength. In these conditions, the Debye length was significantly smaller than the size of nanochannels. Accordingly, the results were consistent with the bulk electrolyte conductance (red dashed line in Figure 3A). In contrast, at low ionic strengths $\left(\leq 10^{-4} \mathrm{M}\right)$, we observed a plateau in conductance (in the log-log scale). This occurred when the Debye length approached the nanochannel dimension, and the excess of counter-ions balanced the surface charge, reaching channel electroneutrality [68]. Here, as it directly related to the conductance, the surface charge could be calculated by fitting the results to the equation [69]:

$$
\frac{I}{V}=2 F \mu \sqrt{\left(\frac{\Sigma}{2}\right)^{2}+c_{0}^{2}} \frac{w h}{l}
$$

In Equation (1), $\mathrm{F}, \mu$, and $\Sigma$ are the Faraday's constant, ionic mobility, and the volume charge density, respectively. Further, $c_{0}$ is the solution molarity, and $\mathrm{w}, \mathrm{h}$, and 1 are the nanochannels' width, height, and length, respectively. Using the relation $z F \Sigma=-2 \sigma_{S} / h$, we obtained a surface charge value of $\sigma_{\mathrm{s}}=1.81 \mu \mathrm{C} / \mathrm{m}^{2}$, which was consistent with the previously reported data for SiC surfaces [70]. Our $\mathrm{SiC}$ coating exhibited a surface charge orders of magnitude smaller than $\mathrm{SiO}_{2}\left(1-100 \mathrm{mC} / \mathrm{m}^{2}\right)[71]$, which correlated with better performance in electrostatic gating control. In fact, chemically reactive surfaces act as charge buffers. An externally applied electric field is quickly compensated by protonation or deprotonation of reactive groups on the surface, limiting charge rearrangement in the electrical double layer (EDL) [72]. Thus, to minimize surface charge, materials are often artificially treated [28].

A

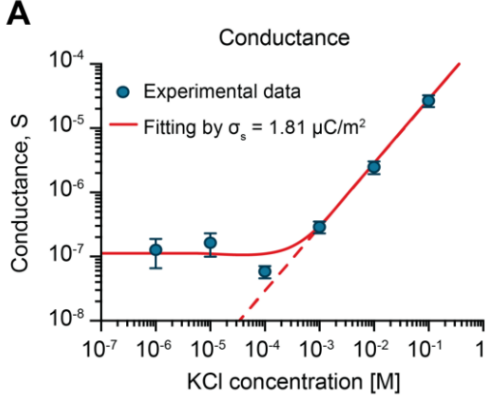

C

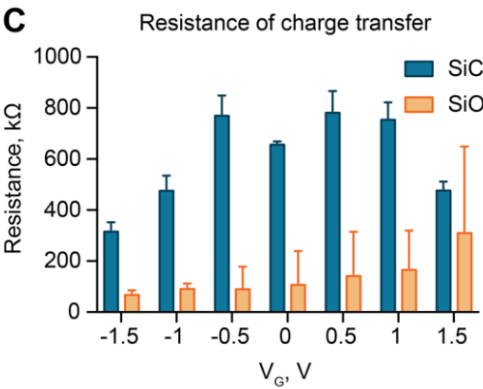

B

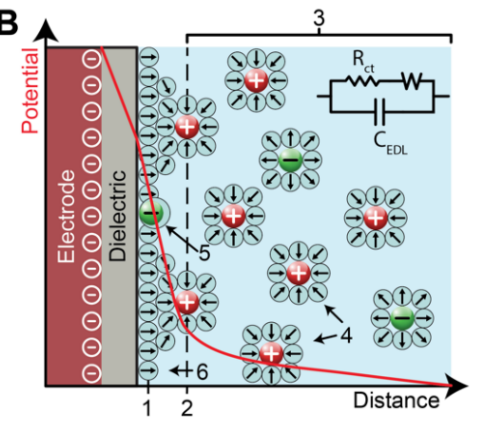

D

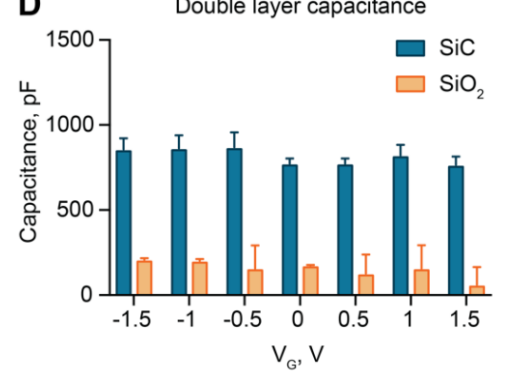

Figure 3. Electrochemical measurements. (A) Measured transmembrane ionic conductance. (B) Schematic of the electric double layer and relative model. (1) Inner Helmholtz plane; (2) Outer Helmholtz plane; (3) Diffuse layer; (4) Solvated ion; (5) Specifically adsorbed ion; (6) Molecules of the electrolyte solvent. $(C)$ Fitted resistance of charge transfer $\left(\mathrm{R}_{\mathrm{ct}}\right)$ of $\mathrm{SiO}_{2}$-coated membranes versus $\mathrm{SiC}$-coated membranes. (D) Fitted double-layer capacitance $\left(\mathrm{C}_{\mathrm{dl}}\right)$ of $\mathrm{SiO}_{2}$-coated membranes versus SiC-coated membranes. 


\subsection{Electrochemical Characterization: Electrochemical Impedance Spectroscopy}

To investigate dielectric/liquid interface properties with the application of an external voltage, we performed electrochemical impedance spectroscopy (EIS) measurements. Specifically, we compared the resistance to charge transfer and the double layer capacitance at different gate voltages. A comparative assessment was conducted using $\mathrm{SiC}$ - and $\mathrm{SiO}_{2}$-coated chips. Figure 3B shows a schematics of the electrical double layer (EDL), which described the ionic distribution that occurres at the solid-liquid interface of a charged surface to maintain local electroneutrality. The EDL is usually described by that Grahame model, which identifies three main layers consisting of 1) non-hydrated ions adsorbed to the surface, ii) hydrated immobile ions, iii) free moving hydrated ions [73]. The first and second layers of immobile ions are often referred to as the Stern layer. The EDL region is modeled by a series of capacitors, referred to as double-layer capacitance $\left(C_{E D L}\right)$, where the Stern layer $(\sim 0.2 \mathrm{~nm})$ [74] corresponds to the most significant contribution. As current can flow across the interface upon application of a DC potential, a resistive path is considered in parallel to the capacitance. This is usually referred to as a charge-transfer resistance $\left(R_{c t}\right)$. $R_{c t}$ can vary substantially depending on the material ability to exchange electrons with the electrolyte solution. Upon application of an external DC potential, if electrons cannot be easily exchanged, an overpotential builds up at the interface. In non-polarizable materials, such as $\mathrm{Ag} / \mathrm{AgCl}$, small $R_{\mathrm{ct}}$ permits high currents. In contrast, polarizable materials present high $R_{c t}$, and the current exchange is limited.

By fitting our EIS measurements to the model described above (Figure 3B), we calculated $R_{c t}$ and $\mathrm{C}_{\mathrm{EDL}}$ for both a $\mathrm{SiO}_{2}$ - and a SiC-coated membrane at different gate voltages $\left(\mathrm{V}_{\mathrm{G}}\right)$ applied (Figure $\left.3 \mathrm{C}, \mathrm{D}\right)$. Depending on the applied potential, $\mathrm{SiC}$ showed an $\mathrm{R}_{\mathrm{ct}} 1.5$ to 8 times bigger than $\mathrm{SiO}_{2}$ (Figure 3C). Interestingly, both materials showed a clear dependence of $\mathrm{R}_{\mathrm{ct}}$ with the applied voltage. $\mathrm{SiO}_{2}$ exhibited a monotonic increase of $R_{c t}$ with the applied voltage, where more positive voltages resulted in higher $\mathrm{R}_{\mathrm{ct}}$. In contrast, $\mathrm{SiC}$ showed a decrease in $\mathrm{R}_{\mathrm{ct}}$ proportional to the absolute value of the applied voltage. We attributed these phenomena to the difference in surface charge between $\mathrm{SiO}_{2}$ and $\mathrm{SiC}$. In fact, a higher number of available $\mathrm{SiO}^{-}$sites on the $\mathrm{SiO}_{2}$ surface allowed for increased electron exchange.

$\mathrm{C}_{\mathrm{EDL}}$ did not exhibit a correlation with the applied gate voltage for either material (Figure 3D). Moreover, we unexpectedly found six times higher $\mathrm{C}_{\mathrm{EDL}}$ for $\mathrm{SiC}$ with respect to $\mathrm{SiO}_{2}$. As $\mathrm{C}_{\mathrm{EDL}}$ mainly depends on the surface area and EDL thickness, our results could be explained in the context of the material porosity [75]. By presenting a larger surface area, pores displayed increased capacity. Overall, the low surface charge exposed by $\mathrm{SiC}$ and the high resistance to charge transfer qualified $\mathrm{SiC}$ as a polarizable interface suitable for electrostatic gating.

\subsection{Mechanism of Analyte Flow Control through Electrostatic Gating}

Nanofluidic systems present high surface to volume ratios. In light of this, charged species diffusing in nanoconfinement exhibit unique behaviors [76,77]. Electrostatic, steric, and hydrodynamic interactions with the nanochannel walls influence local molecular concentration and effective diffusivity. Depending on solution properties, such as ionic strength, $\mathrm{pH}$, and surface charge density, the EDL can extend from a fraction to hundreds of $\mathrm{nm}$ in the fluid. Both $\mathrm{SiC}$ and $\mathrm{SiO}_{2}$ surface expose native silanol groups, resulting in a net negative surface charge at $\mathrm{pH} 7.4$ [78]. In proximity to the surface, charged species redistribute to reach electroneutrality [73]. While counter-ions concentration increases, co-ions are depleted following distribution with a characteristic dimension equal to the Debye length.

Once solution properties are defined, the surface charge is the only parameter that has a significant effect on the distribution of charges in the fluid. Thus, nanochannel charge-selectivity can be altered by controlling the channel surface charge. An applied difference in potential between a buried gate electrode and an electrode in solution creates an overpotential at the surface. We employed this strategy to modulate the diffusive transport of analytes through our nanofluidic membrane. With no applied voltage, molecules diffused through the channel unperturbed. By applying a negative gate potential, the transmembrane transport of co-ions was substantially reduced. 


\subsection{In Vitro Release Modulation of Methotrexate}

To investigate the effectiveness of electrostatic gating on controlling trans-membrane transport of a small charged analyte, we performed an in vitro diffusion study using methotrexate. Methotrexate has a molecular weight of $454 \mathrm{Da}$ and is a good representative of small molecules (<900 Da) therapeutics, which accounts for the majority of pharmaceuticals [79]. Clinically, methotrexate is used as a chemotherapeutic agent for the treatment of various cancers, as well as in the management of rheumatoid arthritis [33].

Figure $4 \mathrm{~A}$ shows the normalized release rates for four consecutive cycles alternating between passive and active phases. During the passive phases, negatively charged molecules $(-2 q$ for methotrexate) diffused trough the nanochannels freely, largely unaffected by the low native charge of the $\mathrm{SiC}$ surfaces. When a negative voltage was applied $(-3 \mathrm{~V})$, an increase in negative surface charge repelled methotrexate molecules, reducing their release. The four alternation cycles between passive and active phases demonstrated that electrostatic gating allowed for repeatability of release modulation.
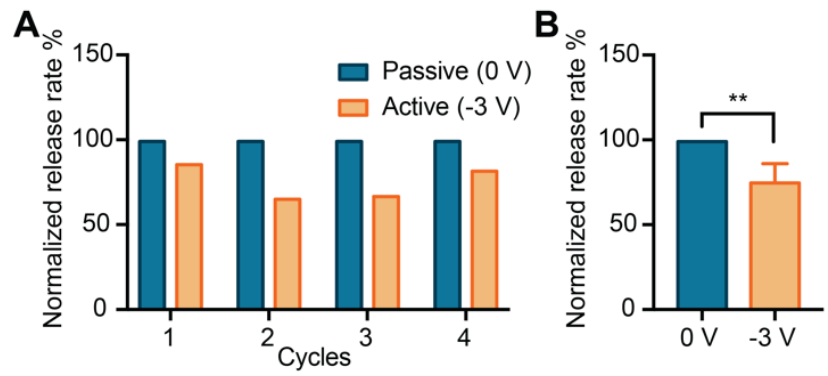

Figure 4. Electrostatically controlled release of methotrexate. (A) The normalized release rate of methotrexate for four cycles between free diffusion (Passive) and gated diffusion (Active). (B) Release rates grouped by phase typology $(* * p \leq 0.01)$.

We observed a statistically significant $\left({ }^{*} p \leq 0.01\right)$ difference in release rate between active and passive phases, whereby the applied potential $-3 \mathrm{~V}$ yielded a decrease in the release rate of $\sim 35 \%$. During the passive phase, an average release rate of $10 \mu \mathrm{g} /$ day was obtained, which was consistent with daily doses used to treat rheumatoid arthritis in pre-clinical testing [80]. Other small molecule therapeutics, including glucocorticoids [81], hormone therapeutics [82], and antivirals [83], present effective daily doses in the order of micrograms. This indicates that the current membrane architecture could, in principle, be adopted for various therapeutic applications. However, further testing with different pharmaceutical agents is warranted.

\subsection{In Vitro Controlled Release of Quantum Dots}

To assess the ability of our membrane to modulate the release rate of larger molecules, we performed an in vitro release study with quantum dots. Quantum dots possess broad applicability in bioengineering, including imaging [84], theranostics [85], cell labeling for in vivo tracking [86], tissue staining [87]. They have also been investigated as biomarkers for cancer detection and for targeted drug delivery [35]. Figure 5A shows the normalized release rate of each phase, where passive $(0 \mathrm{~V})$ and active phases $(-1.5 \mathrm{~V})$ were alternated over three cycles.

The application of the negative gate potential drastically reduced the release of quantum dots from the membrane. Subsequent cycles demonstrated consistent and reproducible release rate reduction, suggesting that the membrane and the gating performance were consistent over time. A statistically significant difference $\left({ }^{* * *} p \leq 0.0001\right)$ in the release between active and passive phases $(84 \%)$ was observed (Figure 5B). When compared to methotrexate, quantum dots clearly showed a more effective electrostatic modulation, which could be attributed to higher particle charge and lower ionic strength of the solution. Specifically, the high exposed charge is due to the carboxylic functionalization, where several groups result in a negative net charge that ranges from -5 to -15 depending on $\mathrm{pH}$ and 
ionic strength [41]. Moreover, the low ionic strength solution $(0.01 \times$ PBS $)$ has a Debye length 10 times greater than the $1 \times$ PBS. These two properties contribute to enhance the electrostatic interactions between the wall and the solute. Thus, the application of the gate potential resulted in increased efficacy of release modulation.
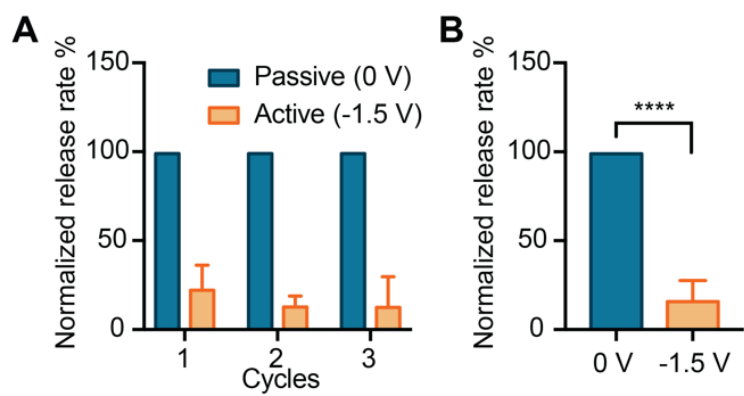

Figure 5. Electrostatically controlled release of quantum dots. (A) The normalized release rate of quantum dots for three cycles between free diffusion (Passive) and gated diffusion (Active). (B) Release rates grouped by phase typology $\left.{ }^{* * * *} p \leq 0.0001\right)$.

\subsection{Considerations on Electrostatic Gating Performance}

To achieve efficient devices for tunable molecular diffusion via electrostatic gating, various parameters need to be optimized. Of utmost importance is the choice of dielectric material to insulate the buried gate electrode. In this study, we investigated $\mathrm{SiC}$ as it conciliates the need for low leakage currents, with a dielectric constant similar to $\mathrm{SiO}_{2}$ (4.4-4.9) [88], and offers chemical inertness in aqueous solutions [48]. Moreover, SiC offers a low native charge; therefore, it minimizes unwanted non-linearities connected to the buffer capacity of strongly charged surfaces [72].

Further, efficient electrostatic flow modulation is strictly connected to the nanochannel size to the Debye length ratio $(h / \lambda)$. Our membrane was designed for medical applications, where the ionic strength and $\mathrm{pH}$ were bound to physiological values. Our future investigations focus on manufacturing membranes with smaller nanochannels to be able, in principle, to completely stop analyte diffusion. Finally, as flow control trough electrostatic gating is mainly based on coulombic interactions, analytes that expose high surface charges are more suitable for gate modulation. Therefore, drug encapsulation with highly charged polymers can significantly improve administration control of small analytes.

\section{Conclusions}

In this work, we investigated a SiC-coated nanofluidic membrane capable of the reproducible control of analyte transport via electrostatic gating. The application of a low-intensity electrical potential to the gate electrode allowed us to alter nanochannel surface charge, leading to tunable membrane charge-selectivity, and control over the release of methotrexate and quantum dots. Electrochemical characterization showed that $\mathrm{SiC}$ dielectric coating exhibited low leakage current and reduced intrinsic charge as compared to $\mathrm{SiO}_{2}$. Moreover, SiC offered chemical bioinertness, which rendered it an ideal candidate for use in biomedical devices for therapeutic delivery based on electrostatic-gating. In this context, our membranes could be employed as actuators for remotely controlled drug delivery systems. The low voltage needed to modulate the release rate could be provided via small scale and low-power circuitry. This investigation might pave the way for the development of the next generation of drug delivery systems, enabling pre-programmed or remotely managed pharmaceutic administration. Further, our gated nanofluidic membrane might find applicability in molecular sieving and lab on a chip diagnostic. 


\section{Patents}

Grattoni, A.; Liu, X.; Ferrari, M. Gated Nanofluidic Valve For Active And Passive Electrosteric Control Of Molecular Transport, And Methods Of Fabrication, U.S. Provisional Pat. Ser. No. 62/961,437, filed Jan 15. (2020).

Author Contributions: Conceptualization, N.D.T., A.S., X.L., and A.G.; Data curation, N.D.T; Formal analysis, N.D.T and A.S.; Funding acquisition, X.L. and A.G.; Investigation, N.D.T., A.S., and Y.W.; Methodology, N.D.T., A.S., Y.W., and X.L.; Project administration, A.G.; Resources, X.L., and A.G.; Software, N.D.T.; Supervision, D.D. and A.G.; Validation, D.D., X.L., and A.G.; Visualization, N.D.T.; Writing-original draft, N.D.T.; Writing-review and editing, A.G. All authors have read and agreed to the published version of the manuscript.

Funding: The support was provided by the Houston Methodist Research Institute and NIH-NIGMS R01GM127558 (A.G.). A.G. and research group received additional support through the Frank J. and Jean Raymond Centennial Chair Endowment, and N.D.T. received funding support from the Chinese Academy of Sciences and The World Academy of Sciences through the CAS-TWAS President's fellowship scholarship.

Acknowledgments: We thank Valentina Serafini for her support in experimental studies and Jianhua (James) Gu from the electron microscopy core of the Houston Methodist Research Institute.

Conflicts of Interest: The authors declare no conflict of interest.

\section{References}

1. Hajat, C.; Stein, E. The global burden of multiple chronic conditions: A narrative review. Prev. Med. Rep. 2018, 12, 284-293. [CrossRef] [PubMed]

2. Yach, D.; Leeder, S.R.; Bell, J.; Kistnasamy, B. Global chronic diseases. AAAS. 2005, 307, 317. [CrossRef] [PubMed]

3. World Health Organization. Global Status Report on Noncommunicable Diseases 2014; WHO Press: Geneva, Switzerland, 2014.

4. Divo, M.; Cote, C.; de Torres, J.P.; Casanova, C.; Marin, J.M.; Pinto-Plata, V.; Zulueta, J.; Cabrera, C.; Zagaceta, J.; Hunninghake, G. Comorbidities and risk of mortality in patients with chronic obstructive pulmonary disease. Am. J. Respi. Crit. Care Med. 2012, 186, 155-161. [CrossRef] [PubMed]

5. Lemstra, M.; Nwankwo, C.; Bird, Y.; Moraros, J. Primary nonadherence to chronic disease medications: A meta-analysis. Patient Prefer. Adherence 2018, 12, 721. [CrossRef]

6. García-Lizana, F.; Sarría-Santamera, A. New technologies for chronic disease management and control: A systematic review. J. Telemed. Telecare. 2007, 13, 62-68. [CrossRef]

7. Desai, T.A.; Hansford, D.J.; Ferrari, M. Micromachined interfaces: New approaches in cell immunoisolation and biomolecular separation. Biomol. Eng. 2000, 17, 23-36. [CrossRef]

8. Peng, L.; Mendelsohn, A.D.; LaTempa, T.J.; Yoriya, S.; Grimes, C.A.; Desai, T.A. Long-term small molecule and protein elution from TiO2 nanotubes. Nano Lett 2009, 9, 1932-1936. [CrossRef]

9. Pons-Faudoa, F.P.; Ballerini, A.; Sakamoto, J.; Grattoni, A. Advanced implantable drug delivery technologies: Transforming the clinical landscape of therapeutics for chronic diseases. Biomed. Microdevices 2019, $21,47$. [CrossRef]

10. Chua, C.Y.X.; Jain, P.; Ballerini, A.; Bruno, G.; Hood, R.L.; Gupte, M.; Gao, S.; Di Trani, N.; Susnjar, A.; Shelton, K.; et al. Transcutaneously refillable nanofluidic implant achieves sustained level of tenofovir diphosphate for HIV pre-exposure prophylaxis. J. Controlled Release 2018, 286, 315-325. [CrossRef]

11. Ballerini, A.; Chua, C.Y.X.; Rhudy, J.; Susnjar, A.; Di Trani, N.; Jain, P.R.; Laue, G.; Lubicka, D.; Shirazi-Fard, Y.; Ferrari, M. Counteracting Muscle Atrophy on Earth and in Space via Nanofluidics Delivery of Formoterol. Adv. Ther. 2020, 3, 2000014. [CrossRef]

12. Hermida, R.C.; Ayala, D.E.; Smolensky, M.H.; Mojón, A.; Fernández, J.R.; Crespo, J.J.; Moyá, A.; Rios, M.T.; Portaluppi, F. Chronotherapy improves blood pressure control and reduces vascular risk in CKD. Nat. Rev. Nephrol. 2013, 9, 358. [CrossRef] [PubMed]

13. Lin, S.-Y.; Kawashima, Y. Current status and approaches to developing press-coated chronodelivery drug systems. J. Controlled Release 2012, 157, 331-353. [CrossRef] [PubMed]

14. Iwasaki, Y.; Sendo, M.; Dezaki, K.; Hira, T.; Sato, T.; Nakata, M.; Goswami, C.; Aoki, R.; Arai, T.; Kumari, P. GLP-1 release and vagal afferent activation mediate the beneficial metabolic and chronotherapeutic effects of D-allulose. Nat. Commun. 2018, 9, 1-17. [CrossRef] [PubMed] 
15. Fifel, K.; Videnovic, A. Chronotherapies for Parkinson's disease. Prog. Neurobiol. 2019, 174, 16-27. [CrossRef]

16. Kaur, G.; Phillips, C.; Wong, K.; Saini, B. Timing is important in medication administration: A timely review of chronotherapy research. Int J. Clin. Pharm. 2013, 35, 344-358. [CrossRef]

17. Sprintz, M.; Tasciotti, E.; Allegri, M.; Grattoni, A.; Driver Larry, C.; Ferrari, M. Nanomedicine: Ushering in a new era of pain management. Eur. J. Pain Suppl. 2012, 5, 317-322. [CrossRef]

18. Celler, B.G.; Lovell, N.H.; Basilakis, J. Using information technology to improve the management of chronic disease. Med. J. Aust. 2003, 179, 242-246. [CrossRef]

19. Milani, R.V.; Bober, R.M.; Lavie, C.J. The role of technology in chronic disease care. Prog. Cardiovasc. Dis. 2016, 58, 579-583. [CrossRef]

20. Coye, M.J.; Haselkorn, A.; DeMello, S. Remote patient management: Technology-enabled innovation and evolving business models for chronic disease care. Health Aff. 2009, 28, 126-135. [CrossRef]

21. Hoare, T.; Timko, B.P.; Santamaria, J.; Goya, G.F.; Irusta, S.; Lau, S.; Stefanescu, C.F.; Lin, D.; Langer, R.; Kohane, D.S. Magnetically triggered nanocomposite membranes: A versatile platform for triggered drug release. Nano Lett. 2011, 11, 1395-1400. [CrossRef]

22. Timko, B.P.; Arruebo, M.; Shankarappa, S.A.; McAlvin, J.B.; Okonkwo, O.S.; Mizrahi, B.; Stefanescu, C.F.; Gomez, L.; Zhu, J.; Zhu, A.; et al. Near-infrared-actuated devices for remotely controlled drug delivery. Proc. Natl. Acad. Sci. USA 2014, 111, 1349-1354. [CrossRef] [PubMed]

23. Kim, K.; Jo, M.-C.; Jeong, S.; Palanikumar, L.; Rotello, V.M.; Ryu, J.-H.; Park, M.-H. Externally controlled drug release using a gold nanorod contained composite membrane. Nanoscale 2016, 8, 11949-11955. [CrossRef] [PubMed]

24. Kumeria, T.; Yu, J.; Alsawat, M.; Kurkuri, M.D.; Santos, A.; Abell, A.D.; Losic, D. Photoswitchable Membranes Based on Peptide-Modified Nanoporous Anodic Alumina: Toward Smart Membranes for On-Demand Molecular Transport. Adv. Mater. 2015, 27, 3019-3024. [CrossRef]

25. Ferrara, K.W. Driving delivery vehicles with ultrasound. Adv. Drug Deliver Rev. 2008, 60, 1097-1102. [CrossRef]

26. Lee, S.H.; Piao, H.; Cho, Y.C.; Kim, S.N.; Choi, G.; Kim, C.R.; Ji, H.B.; Park, C.G.; Lee, C.; Shin, C.I.; et al. Implantable multireservoir device with stimulus-responsive membrane for on-demand and pulsatile delivery of growth hormone. Proc. Natl. Acad. Sci. USA 2019, 116, 11664-11672. [CrossRef] [PubMed]

27. Farina, M. Remote magnetic switch off microgate for nanofluidic drug delivery implants. Biomed. Microdevices 2017, 19, 42. [CrossRef]

28. Kim, S.; Ozalp, E.I.; Darwish, M.; Weldon, J.A. Electrically gated nanoporous membranes for smart molecular flow control. Nanoscale 2018, 10, 20740-20747. [CrossRef]

29. Jeon, G.; Yang, S.Y.; Byun, J.; Kim, J.K. Electrically actuatable smart nanoporous membrane for pulsatile drug release. Nano Lett. 2011, 11, 1284-1288. [CrossRef]

30. Zhang, Q.; Kang, J.; Xie, Z.; Diao, X.; Liu, Z.; Zhai, J. Highly Efficient Gating of Electrically Actuated Nanochannels for Pulsatile Drug Delivery Stemming from a Reversible Wettability Switch. Adv. Mater. 2018, 30, 1703323. [CrossRef]

31. Kostaras, C.; Dellis, S.; Christoulaki, A.; Anastassopoulos, D.L.; Spiliopoulos, N.; Vradis, A.; Toprakcioglu, C.; Priftis, G.D. Flow through polydisperse pores in an anodic alumina membrane: A new method to measure the mean pore diameter. J. Appl. Phys. 2018, 124, 204307. [CrossRef]

32. Grattoni, A.; Liu, X.; Ferrari, M. Gated Nanofluidic Valve For Active And Passive Electrosteric Control Of Molecular Transport, And Methods Of Fabrication. U.S. Patent 62/961,437, 15 January 2020.

33. Lopez-Olivo, M.A.; Siddhanamatha, H.R.; Shea, B.; Tugwell, P.; Wells, G.A.; Suarez-Almazor, M.E. Methotrexate for treating rheumatoid arthritis. Cochrane Database Syst. Rev. 2014. [CrossRef] [PubMed]

34. Matea, C.T.; Mocan, T.; Tabaran, F.; Pop, T.; Mosteanu, O.; Puia, C.; Iancu, C.; Mocan, L. Quantum dots in imaging, drug delivery and sensor applications. Int J. Nanomed. 2017, 12, 5421-5431. [CrossRef]

35. Cheki, M.; Moslehi, M.; Assadi, M. Marvelous applications of quantum dots. Eur Rev. Med. Pharmacol. Sci. 2013, 17, 1141-1148. [PubMed]

36. Napoli, M.; Eijkel, J.C.; Pennathur, S. Nanofluidic technology for biomolecule applications: A critical review. Lab Chip 2010, 10, 957-985. [CrossRef] [PubMed]

37. Lu, Y.; Liu, T.; Lamanda, A.C.; Sin, M.L.; Gau, V.; Liao, J.C.; Wong, P.K. AC electrokinetics of physiological fluids for biomedical applications. J. Lab. Autom. 2015, 20, 611-620. [CrossRef] [PubMed] 
38. Gao, J.; Riahi, R.; Sin, M.L.; Zhang, S.; Wong, P.K. Electrokinetic focusing and separation of mammalian cells in conductive biological fluids. Analyst 2012, 137, 5215-5221. [CrossRef]

39. Di Trani, N.; Silvestri, A.; Sizovs, A.; Wang, Y.; Erm, D.R.; Demarchi, D.; Liu, X.; Grattoni, A. Electrostatically gated nanofluidic membrane for ultra-low power controlled drug delivery. Lab Chip 2020, 20, 1562-1576. [CrossRef]

40. Grattoni, A.; Gill, J.; Zabre, E.; Fine, D.; Hussain, F.; Ferrari, M. Device for rapid and agile measurement of diffusivity in micro- and nanochannels. Anal. Chem. 2011, 83, 3096-3103. [CrossRef]

41. Voráčová, I.; Klepárník, K.; Lišková, M.; Foret, F. Determination of $\zeta$-potential, charge, and number of organic ligands on the surface of water soluble quantum dots by capillary electrophoresis. Electrophoresis 2015, 36, 867-874. [CrossRef]

42. Swain, M. Chemicalize.org. J. Chem. Inf. Model. 2012, 52, 613-615. [CrossRef]

43. Haro-González, P.; Martínez-Maestro, L.; Martín, I.; García-Solé, J.; Jaque, D. High-Sensitivity Fluorescence Lifetime Thermal Sensing Based on CdTe Quantum Dots. Small 2012, 8, 2652-2658. [CrossRef] [PubMed]

44. Geninatti, T.; Small, E.; Grattoni, A. Robotic UV-Vis apparatus for long-term characterization of drug release from nanochannels. Meas. Sci. Technol. 2014, 25. [CrossRef]

45. Scorrano, G.; Bruno, G.; Di Trani, N.; Ferrari, M.; Pimpinelli, A.; Grattoni, A. Gas Flow at the Ultra-nanoscale: Universal Predictive Model and Validation in Nanochannels of Ångstrom-Level Resolution. ACS Appl. Mater. Interfaces 2018, 10, 32233-32238. [CrossRef] [PubMed]

46. Kotzar, G.; Freas, M.; Abel, P.; Fleischman, A.; Roy, S.; Zorman, C.; Moran, J.M.; Melzak, J. Evaluation of MEMS materials of construction for implantable medical devices. Biomaterials 2002, 23, 2737-2750. [CrossRef]

47. Voskerician, G.; Shive, M.S.; Shawgo, R.S.; Von Recum, H.; Anderson, J.M.; Cima, M.J.; Langer, R. Biocompatibility and biofouling of MEMS drug delivery devices. Biomaterials 2003, 24, 1959-1967. [CrossRef]

48. Oliveros, A.; Guiseppi-Elie, A.; Saddow, S.E. Silicon carbide: A versatile material for biosensor applications. Biomed. Microdevices 2013, 15, 353-368. [CrossRef] [PubMed]

49. Mahmoodi, M.; Ghazanfari, L. Physics and Technology of Silicon Carbide Devices; Hijikata, Y, Ed.; InTech: Vienna, Austria, 2012.

50. Cogan, S.F.; Edell, D.J.; Guzelian, A.A.; Ping Liu, Y.; Edell, R. Plasma-enhanced chemical vapor deposited silicon carbide as an implantable dielectric coating. J. Biomed. Mater. Res. 2003, 67, 856-867. [CrossRef]

51. Zorman, C.A.; Eldridge, A.; Du, J.G.; Johnston, M.; Dubnisheva, A.; Manley, S.; Fissell, W.; Fleischman, A.; Roy, S. Amorphous Silicon Carbide as a Non-Biofouling Structural Material for Biomedical Microdevices; Materials Science Forum, Trans Tech Publications Ltd.: Stafa-Zurich, Switzerland, 2012; pp. 537-540. [CrossRef]

52. Takami, Y.; Yamane, S.; Makinouchi, K.; Otsuka, G.; Glueck, J.; Benkowski, R.; Nosé, Y. Protein adsorption onto ceramic surfaces. J. Biomed. Mater. Res. 1998, 40, 24-30. [CrossRef]

53. Ferrati, S.; Nicolov, E.; Zabre, E.; Geninatti, T.; Shirkey, B.A.; Hudson, L.; Hosali, S.; Crawley, M.; Khera, M.; Palapattu, G.; et al. The Nanochannel Delivery System for Constant Testosterone Replacement Therapy. J. Sex. Med. 2015, 12, 1375-1380. [CrossRef]

54. Pons-Faudoa, F.P.; Sizovs, A.; Shelton, K.A.; Momin, Z.; Bushman, L.R.; Chua, C.Y.X.; Nichols, J.E.; Hawkins, T.; Rooney, J.F.; Marzinke, M.A. Preventive efficacy of a tenofovir alafenamide fumarate nanofluidic implant in SHIV-challenged nonhuman primates. BioRxiv. 2020. [CrossRef]

55. Bruno, G.; Canavese, G.; Liu, X.; Filgueira, C.S.; Sacco, A.; Demarchi, D.; Ferrari, M.; Grattoni, A. The active modulation of drug release by an ionic field effect transistor for an ultra-low power implantable nanofluidic system. Nanoscale 2016, 8, 18718-18725. [CrossRef] [PubMed]

56. Ferrati, S.; Fine, D.; You, J.; De Rosa, E.; Hudson, L.; Zabre, E.; Hosali, S.; Zhang, L.; Hickman, C.; Sunder Bansal, S.; et al. Leveraging nanochannels for universal, zero-order drug delivery in vivo. J. Controlled Release 2013, 172, 1011-1019. [CrossRef] [PubMed]

57. Di Trani, N.; Jain, P.; Chua, C.Y.X.; Ho, J.S.; Bruno, G.; Susnjar, A.; Pons-Faudoa, F.P.; Sizovs, A.; Hood, R.L.; Smith, Z.W.; et al. Nanofluidic microsystem for sustained intraocular delivery of therapeutics. Nanomed. Nanotechnol. Biol. Med. 2019, 16, 1-9. [CrossRef] [PubMed]

58. Fine, D.; Grattoni, A.; Hosali, S.; Ziemys, A.; De Rosa, E.; Gill, J.; Medema, R.; Hudson, L.; Kojic, M.; Milosevic, M.; et al. A robust nanofluidic membrane with tunable zero-order release for implantable dose specific drug delivery. Lab Chip 2010, 10, 3074-3083. [CrossRef] [PubMed] 
59. Di Trani, N.; Silvestri, A.; Bruno, G.; Geninatti, T.; Chua, C.Y.X.; Gilbert, A.; Rizzo, G.; Filgueira, C.S.; Demarchi, D.; Grattoni, A. Remotely controlled nanofluidic implantable platform for tunable drug delivery. Lab.Chip 2019, 19, 2192-2204. [CrossRef] [PubMed]

60. Fine, D.; Grattoni, A.; Zabre, E.; Hussein, F.; Ferrari, M.; Liu, X. A low-voltage electrokinetic nanochannel drug delivery system. Lab Chip 2011, 11, 2526-2534. [CrossRef]

61. Prakash, S.; Conlisk, A.T. Field effect nanofluidics. Lab Chip 2016, 16, 3855-3865. [CrossRef]

62. Plecis, A.; Tazid, J.; Pallandre, A.; Martinhon, P.; Deslouis, C.; Chen, Y.; Haghiri-Gosnet, A. Flow field effect transistors with polarisable interface for EOF tunable microfluidic separation devices. Lab Chip 2010, 10, 1245-1253. [CrossRef]

63. Robertson, J. High dielectric constant gate oxides for metal oxide Si transistors. Rep. Prog. Phys. 2005, 69, 327-396. [CrossRef]

64. Padovani, A.; Gao, D.Z.; Shluger, A.L.; Larcher, L. A microscopic mechanism of dielectric breakdown in SiO2 films: An insight from multi-scale modeling. J. Appl. Phys. 2017, 121, 155101. [CrossRef]

65. Yao, J.; Zhong, L.; Natelson, D.; Tour, J.M. In situ imaging of the conducting filament in a silicon oxide resistive switch. Sci. Rep. 2012, 2, 1-5. [CrossRef] [PubMed]

66. Tung, C.H.; Pey, K.L.; Tang, L.J.; Radhakrishnan, M.K.; Lin, W.H.; Palumbo, F.; Lombardo, S. Percolation path and dielectric-breakdown-induced-epitaxy evolution during ultrathin gate dielectric breakdown transient. Appl. Phys. Lett. 2003, 83, 2223-2225. [CrossRef]

67. Chen, X.; Wang, H.; Sun, G.; Ma, X.; Gao, J.; Wu, W. Resistive switching characteristic of electrolyte-oxide-semiconductor structures. J. Semicond. 2017, 38, 8. [CrossRef]

68. Daiguji, H.; Yang, P.; Majumdar, A. Ion transport in nanofluidic channels. Nano Lett. 2004, 4, 137-142. [CrossRef]

69. Yossifon, G.; Mushenheim, P.; Chang, Y.-C.; Chang, H.-C. Nonlinear current-voltage characteristics of nanochannels. Phys. Rev. E 2009. [CrossRef]

70. Grosjean, A.; Rezrazi, M.; Tachez, M. Study of the surface charge of silicon carbide (SIC) particles for electroless composite deposits: Nickel-SiC. Surf. Coat. Technol. 1997, 96, 300-304. [CrossRef]

71. Karnik, R.; Fan, R.; Yue, M.; Li, D.; Yang, P.; Majumdar, A. Electrostatic control of ions and molecules in nanofluidic transistors. Nano lett. 2005, 5, 943-948. [CrossRef]

72. Jiang, Z.; Stein, D. Electrofluidic Gating of a Chemically Reactive Surface. Langmuir 2010, 26, 8161-8173. [CrossRef]

73. Schoch, R.B.; Han, J.; Renaud, P. Transport phenomena in nanofluidics. Rev. Mod. Phys. 2008, 80, 839-883. [CrossRef]

74. Herbowski, L.; Gurgul, H.; Staron, W. Experimental determination of the Stern layer thickness at the interface of the human arachnoid membrane and the cerebrospinal fluid. Z. Med. Phys. 2009, 19, 189-192. [CrossRef]

75. Lu, P.; Dai, Q.; Wu, L.; Liu, X. Structure and Capacitance of Electrical Double Layers at the Graphene-Ionic Liquid Interface. Appl. Sci. 2017, 7, 939. [CrossRef]

76. Bruno, G.; Di Trani, N.; Hood, R.L.; Zabre, E.; Filgueira, C.S.; Canavese, G.; Jain, P.; Smith, Z.; Demarchi, D.; Hosali, S. Unexpected behaviors in molecular transport through size-controlled nanochannels down to the ultra-nanoscale. Nat. Commun. 2018, 9, 1682. [CrossRef] [PubMed]

77. Di Trani, N.; Pimpinelli, A.; Grattoni, A. Finite-Size Charged Species Diffusion and pH Change in Nanochannels. ACS Appl. Mater. Interfaces 2020, 12, 12246-12255. [CrossRef] [PubMed]

78. Behrens, S.H.; Grier, D.G. The charge of glass and silica surfaces. J Chem. Phys. 2001, 115, 6716-6721. [CrossRef]

79. Veber, D.F.; Johnson, S.R.; Cheng, H.-Y.; Smith, B.R.; Ward, K.W.; Kopple, K.D. Molecular Properties That Influence the Oral Bioavailability of Drug Candidates. J. Med. Chem. 2002, 45, 2615-2623. [CrossRef]

80. Liu, D.Y.; Lon, H.K.; Wang, Y.L.; DuBois, D.C.; Almon, R.R.; Jusko, W.J. Pharmacokinetics, pharmacodynamics and toxicities of methotrexate in healthy and collagen-induced arthritic rats. Biopharm. Drug Dispos. 2013, 34, 203-214. [CrossRef]

81. Yasin, M.N.; Svirskis, D.; Seyfoddin, A.; Rupenthal, I.D. Implants for drug delivery to the posterior segment of the eye: A focus on stimuli-responsive and tunable release systems. J. Controlled Release 2014, 196, $208-221$. [CrossRef]

82. Langer, R.D. Efficacy, Safety, and Tolerability of Low-Dose Hormone Therapy in Managing Menopausal Symptoms. J Am. Board Fam. Med. 2009, 22, 563. [CrossRef] 
83. Charles, N.C.; Steiner, G.C. Ganciclovir intraocular implant. A clinicopathologic study. Ophthalmology 1996, 103, 416-421. [CrossRef]

84. Li, J.; Zhu, J.-J. Quantum dots for fluorescent biosensing and bio-imaging applications. Analyst 2013, 138, 2506-2515. [CrossRef] [PubMed]

85. Ho, Y.-P.; Leong, K.W. Quantum dot-based theranostics. Nanoscale 2010, 2, 60-68. [CrossRef]

86. Kim, J.; Song, S.H.; Jin, Y.; Park, H.-J.; Yoon, H.; Jeon, S.; Cho, S.-W. Multiphoton luminescent graphene quantum dots for in vivo tracking of human adipose-derived stem cells. Nanoscale 2016, 8, 8512-8519. [CrossRef] [PubMed]

87. Bajwa, N.; Mehra, N.K.; Jain, K.; Jain, N.K. Pharmaceutical and biomedical applications of quantum dots. Artif. Cells Nanomed. Biotechnol. 2016, 44, 758-768. [CrossRef]

88. Hsu, J.-M.; Tathireddy, P.; Rieth, L.; Normann, A.R.; Solzbacher, F. Characterization of a-SiCx: H thin films as an encapsulation material for integrated silicon based neural interface devices. Thin Solid Films 2007, 516, 34-41. [CrossRef] [PubMed]

(C) 2020 by the authors. Licensee MDPI, Basel, Switzerland. This article is an open access article distributed under the terms and conditions of the Creative Commons Attribution (CC BY) license (http://creativecommons.org/licenses/by/4.0/). 